\title{
Central composite design optimization of Bismarck Dye oxidation from textile effluent with Fenton's reagent
}

\author{
Maha A. Tony ${ }^{1,2}$ iD \\ Received: 26 July 2019 / Accepted: 30 March 2020 / Published online: 15 April 2020 \\ (C) The Author(s) 2020
}

\begin{abstract}
Coloured wastewater is discharged in a huge amount from textile industry as a result of using synthetic dyes that causes threat water pollution. A simple sol-gel technique was used to synthesis haematite nanocrystals as a source of photoFenton's reagent. The current work is dealing with the mineralization of Bismarck Brown dye (BBD) using such reagent, and the process parameters were optimized using response surface methodology. Central composite design of the two most important variables of the Fenton's reagent process $\left(\mathrm{Fe}^{3+}\right.$ and $\mathrm{H}_{2} \mathrm{O}_{2}$ doses) was employed for the experimental design, and BBD removal was maximized. The suggested model investigated that the dye removal increases with the increasing of both reagents up to a certain limit then decreases afterwards. The reduction percentages of colour and chemical oxygen demand under the optimum operating parameters $\left(37.21 \mathrm{mg} / \mathrm{L}\right.$ of the haematite nanocrystal and $412.31 \mathrm{mg} / \mathrm{L} \mathrm{of}_{2} \mathrm{O}_{2}$ ) are found to be $76.5 \%$ and $73 \%$, respectively. Analysis of variance and the high regression coefficient (98\%) confirm a good estimation of the experimental values by polynomial regression model. Therefore, the exploration of using haematite nanocrystals as a Fenton's reagent source for treating textile effluents is recommended from this study.
\end{abstract}

Keywords Bismarck Brown $\cdot$ Nanocrystals iron oxide $\cdot$ Optimization $\cdot$ Response surface methodology $\cdot$ Ultraviolet light . Wastewater

\section{Introduction}

Due to the rapid development in the textile dying industries and the extensive use of synthetic dyes, wastewater discharges from such industry represent a major environmental pollution issue. Azo dyes are considered the major classes of synthetic dyes since up to $70 \%$ of the dyes used for commercial purposes are azo dyes (Hussein 2012). According to the presence of the azo bonds $(-\mathrm{N}=\mathrm{N}-)$ such dyes are classified to mono-, dia-, tri-azo, etc. In addition, some of those dyes or their precursors are from toxic aromatic amines complexes. Thus, both human and the marine life are seriously affected due to their toxic and highly carcinogenic effect. To develop

Maha A. Tony

dr.maha.tony@gmail.com

$1 \quad$ Civil and Environmental Engineering, West Virginia University, Morgantown, WV 26506-6103, USA

2 Advanced Materials/Solar Energy and Environmental Sustainability (AMSEES) Laboratory, Basic Engineering Science Department, Faculty of Engineering, Menoufia University, Shebin El-Kom, Egypt the environmental performances, different treatment technologies have been applied in order to mange those aquatic effluents (Abu Amr et al. 2014; Kumaravel et al. 2015; Tony et al. 2018). Over the last decades, to overcome the increasing demand of human being for water, several techniques have been developed for industrial wastewater treatment. According to the literature, for instance, some researchers applied non-reagent physical techniques for treatment such as filtration, coagulation and precipitation (Zhao et al. 2009; Kotut et al. 2011; Ashour and Tony 2017). Additionally, some studies reported the application of adsorption methods for wastewater treatment (Parker et al. 2012; Ashour et al. 2014; Torrades and García-Montano 2014; Tony 2019). However, such techniques are not efficient or adequate for treatment since they transfer the pollutant from one phase to another without mineralizing them besides the high cost of maintenance and treatment. Thus, there is an urgent need to improve feasible alternative techniques for treating the industrial wastewater in an economic and viable approach that environmentally friendly and does not produce a second pollution. Recent studies suggested the significant use of the oxidation techniques such as Fenton's reagent as an 
attractive alternative method for treating dyed wastewater (Chen et al. 2012; Torrades and García-Montano 2014).

Recent advances in the wastewater treatment oxidation are the innovative nanomaterials application. Nanomaterials revealed a promising improvement in the hazards and toxic contaminant remediation and removal (Babuponnusami 2014; Tony et al. 2016). Nanomaterial is applied previously as an alternative way to enhance the Fenton's reagent oxidation technique. Nanomaterials as a source of Fenton's reagent have many applications in wastewater treatment with various pollutants, for instance, humic acids (Nie et al. 2010), chlorophenol (Lu et al. 2002) and phenol (Prucek et al. 2002). However, according to the literature, nanocrystals as a source of Fenton's reagent have not been applied so far for treating BBD effluents.

Response surface methodology (RSM), which is a combination of mathematical and statistical procedures, is appropriate for modelling and evaluating the several variables influencing the responses even in the existence of involved interactions. To date, the traditional optimization researches of wastewater processes have focused on one-variable-at a time methodology. However, this study does not consider the cross-effects of the considered variables. Thus, this time consuming method with a lack of accurate optimum values (Torrades and García-Montano 2014; Tony et al. 2011; Mourabet et al. 2017). The main objective of RSM application in the treatment can result in improving the Fenton's reagent process by determining the optimum variables values and maximizing the response with a decrease in the experiments numbers. Also, the extensive literature examination demonstrates none of researchers examined the Fenton's parameters optimization using CCD for BBD removal. In this respect, the present investigation introduces the application of two-variable central composite design (CCD) for $\mathrm{BBD}$ removal using photo Fenton reagent to evaluate the colour $(C)$ removal and COD reduction in the BBD wastewater as dependent variables. The two selected variables applied in this study are nanocrystals dose and hydrogen peroxide reagent as independent variables. Subsequently, the mathematical models correlating $C$ and COD removals of the two variables were established.

\section{Materials}

\section{Wastewater}

The textile dye Bismarck Brown (BBD), with a molecular formula of $\left(\mathrm{C}_{21} \mathrm{H}_{24} \mathrm{~N}_{8} \cdot 2 \mathrm{HCl}\right)$, its molecular weight is $461.39 \mathrm{~g} / \mathrm{mol}$ and water solubility is $11 \mathrm{~g} / \mathrm{L}$ at $25^{\circ} \mathrm{C}$ is the target pollutant in this study. Real textile dying wastewater samples were collected from a service of dying facility of Jeans garments using Bismarck Dye in Menoufia
Governorate, Shebin El-Kom City, north of Egypt between the period of February and April 2018. Wastewater was collected subsequent the washing facilities conducted after the re-dying process to remove the extra dyes. The main characteristics of wastewater are BBD load is $13.28 \mathrm{mg} / \mathrm{L}$, and COD 1240 and the Suspended Solids (SS) are $23 \mathrm{mg} / \mathrm{L}$ with an effluent $\mathrm{pH}$ of 8.0.

\section{Synthesis and Characterization of $\mathrm{Fe}_{2} \mathrm{O}_{3}$ nanocrystals}

Nano-crystalline $\mathrm{Fe}_{2} \mathrm{O}_{3}$ from aqueous solutions of iron chloride precursor was synthesized using a simple sol-gel technique, and the final product is attained after calcination. The synthesized nanocrystals by this method were confirmed using X-ray diffraction (XRD) patterns. IR spectroscopy using FTIR was used for identification of functional groups and confirmed such type of nanocrystals. Also, the surface morphology was performed using transmission electron microscope (TEM), which found the particle size is varied from 6.1 to $18.3 \mathrm{~nm}$ as previously found in our preliminary experiments.

\section{Photochemical reactor and procedures}

A lab-scale batch mode test of the experimental set-up is shown in Fig. 1. A 12 W UV lamp inside a glass sleeve is immersed in a glass container. Firstly, nanocrystals are added to $100 \mathrm{~mL}$ of wastewater solution with $\mathrm{pH} 3.0$ (the optimum $\mathrm{pH}$ according to our preliminary investigation). Thereafter, the reaction is initiated by adding $\mathrm{H}_{2} \mathrm{O}_{2}$ reagent. The reagents are well mixed in the $\mathrm{BBD}$ aqueous solution, and then, the solution is poured to the photoreactor container. All experiments were conducted at room temperature at stirring speed of $800 \mathrm{rpm}$ and $\mathrm{pH} 3.0$. After 10 min of reaction time treatment, the substrate of the treated wastewater samples is subjected to COD and colour removal analysis.

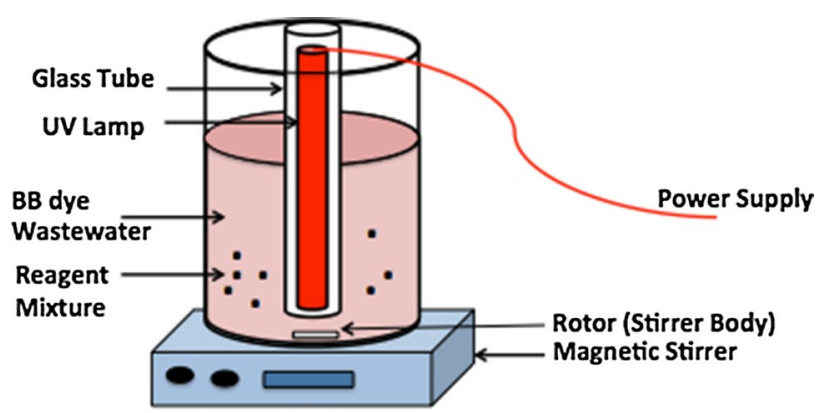

Fig. 1 Scheme methodology of nano-photo-Fenton investigation 


\section{Central composite experimental design (CCD)}

Based on response surface methodology (RSM), central composite experimental design (CCD) technique was chosen to conduct the optimization of the experimental conditions for BBD removal from aqueous solution using photo-Fenton reagent. RSM is a valuable statistical tool that maximizes the response surface affected by operating variables based on a few sets of experiments within a chosen range. RSM is applied widely in the optimization of operating variables (Bhatia et al. 2007), experimental conditions of advanced oxidation process, adsorption processes and biological techniques (Raquel et al. 2015), etc. In this study, CCD is applied for optimization of operating parameters, namely nanocrystals $\mathrm{Fe}_{2} \mathrm{O}_{3}$ dose and $\mathrm{H}_{2} \mathrm{O}_{2}$ reagent concentration for maximizing BBD removal. The leading objectives of BBD reduction are based on colour removal and COD reduction efficiencies of the dyed wastewater. In order to evaluate the process, five levels of the two main factors: nanocrystals $\left(E_{1}\right)$ and $\mathrm{H}_{2} \mathrm{O}_{2}\left(E_{2}\right)$ doses, were chosen as shown in Table 1.

After conducting the experiments, the actual experimental data aimed at developing the model (shown in Table 2) were analysed through least-square method; thus, the correlation of the independent variables and the responses was estimated by the following second-order polynomial model (Khuri and Cornell 1996):

$f_{i}=\beta_{o}+\sum \beta_{i} e_{i}+\sum \beta_{i i} e_{i}^{2}+\sum \sum \beta_{i j} e_{i} e_{j}$

where $f_{i}$ is the predicted response for $C$ and COD removal, respectively; $\beta_{o}, \beta_{i}, \beta_{2}$ and $\beta_{i i}$, are the model coefficient and $e_{1}$ and $e_{2}$ are the independent variables.

RSM was applied to the experimental data using statistical analysis software (SAS) to predict the models through regression analysis and analysis of variance (ANOVA) (SAS 1990). Three-dimensional response surface and two-dimensional contour plots were created by applying Mathematica software (V 5.2) to visualize the interactive effects of the independent factors. Optimum region was also located based on the main parameters in the overlay plot.

\section{Dye removal determinations}

Concentration of wastewater substrate was monitored by measuring both colour removal using spectrophotometric techniques at a wavelength of $526 \mathrm{~nm}$ at the maximum absorbance peak (UV-visible spectrophotometer, model Unico UV-2100, USA). Besides, the measurement of its chemical oxygen demand (COD) following the standard
Table 1 Range and levels of natural and corresponded coded variables for $\mathrm{CCD}$

\begin{tabular}{llllrrrrr}
\hline Variable & \multicolumn{1}{l}{ Symbols } & & \multicolumn{2}{l}{ Range and levels } \\
\cline { 2 - 6 } \cline { 5 - 8 } & Natural & Coded $^{\mathrm{a}}$ & & -1.41421 & -1 & 0 & 1 & 1.41421 \\
\hline $\mathrm{Fe}^{3+}(\mathrm{mg} / \mathrm{L})$ & $e_{1}$ & $E_{1}$ & 11.72 & 20 & 40 & 60 & 68.28 \\
$\mathrm{H}_{2} \mathrm{O}_{2}(\mathrm{mg} / \mathrm{L})$ & $e_{2}$ & $E_{2}$ & 117.2 & 200 & 400 & 600 & 682.8 \\
\hline
\end{tabular}

${ }^{\text {a }}$ Code level $\left(E_{1}=\left(e_{1}-40\right) / 10, E_{2}=\left(e_{2}-400\right) / 200\right.$

\begin{tabular}{|c|c|c|c|c|c|c|c|c|}
\hline \multirow[t]{3}{*}{ Trail no } & \multirow{2}{*}{\multicolumn{2}{|c|}{$\frac{\text { Variables }}{\text { Codified factors }}$}} & \multicolumn{6}{|c|}{ Responses (\%) } \\
\hline & & & \multicolumn{2}{|c|}{ Natural factors } & \multicolumn{2}{|c|}{ Experimental } & \multicolumn{2}{|c|}{ Predicted } \\
\hline & $E_{1}$ & $E_{2}$ & $e_{1}$ & $e_{2}$ & $f_{1}$ & $f_{2}$ & $f_{1}$ & $f_{2}$ \\
\hline 1 & -1 & -1 & 20 & 200 & 54 & 51 & 53 & 49 \\
\hline 2 & -1 & 1 & 20 & 600 & 50 & 52 & 52 & 55 \\
\hline 3 & 1 & -1 & 60 & 200 & 42 & 40 & 41 & 39 \\
\hline 4 & 1 & 1 & 60 & 600 & 47 & 45 & 49 & 45 \\
\hline 5 & -1.41421 & 0 & 11.72 & 400 & 52 & 54 & 53 & 53 \\
\hline 6 & 1.41421 & 0 & 68.28 & 400 & 38 & 40 & 41 & 40 \\
\hline 7 & 0 & -1.41421 & 40 & 117.2 & 45 & 42 & 48 & 44 \\
\hline 8 & 0 & 1.41421 & 40 & 682.3 & 54 & 53 & 54 & 51 \\
\hline 9 & 0 & 0 & 40 & 400 & 75 & 72 & 76 & 72 \\
\hline 10 & 0 & 0 & 40 & 400 & 74 & 71 & 76 & 72 \\
\hline 11 & 0 & 0 & 40 & 400 & 79 & 75 & 76 & 72 \\
\hline 12 & 0 & 0 & 40 & 400 & 77 & 72 & 76 & 72 \\
\hline 13 & 0 & 0 & 40 & 400 & 73 & 70 & 76 & 72 \\
\hline
\end{tabular}

Table 2 The CCD experimental design with two independent variables 
methods (APHA 1998) is conducted. $\mathrm{pH}$ of the wastewater samples was measured and adjusted using a digital $\mathrm{pH}$-meter (AD1030, Adwa instrument, Hungary).

\section{Calculation methods}

BBD dye removal from wastewater was calculated according to the following equations:

$f_{1}=\frac{C_{\mathrm{o}}-C_{\mathrm{t}}}{C_{\mathrm{o}}} \times 100$

$f_{2}=\frac{\mathrm{COD}_{\mathrm{o}}-\mathrm{COD}_{\mathrm{t}}}{\mathrm{COD}_{\mathrm{o}}} \times 100$

where $f_{1}$ and $f_{2}$ were the colour $(C)$ removal and chemical oxygen demand (COD) removal; $C_{\mathrm{o}}, \mathrm{COD}_{\mathrm{o}}$ and $C_{\mathrm{v}}, \mathrm{COD}_{\mathrm{t}}$ were the initial and finial values of $C$ and COD.

\section{Results and discussion}

\section{Mathematical model build-up}

In the present study, photo-Fenton reagent based on the nanocrystalline iron oxide was investigated to treat BBD wastewater under different operational conditions: $\mathrm{Fe}^{3+}$ (11.72-68.28 mg/L) and $\mathrm{H}_{2} \mathrm{O}_{2}(117.2-682.8 \mathrm{mg} / \mathrm{L})$ at the operating $\mathrm{pH}$ 3.0. A central composite design (CCD) was applied as it is very commonly used in the RSM technique and the simple linear or quadratic models can be related to the response values (Colour and COD removals in this study) (Tak et al. 2015). The thirteen experiments are necessary for the design matrix of the two factors $\left(\mathrm{Fe}^{3+}\right.$ and $\mathrm{H}_{2} \mathrm{O}_{2}$ doses) with five levels of each factor, which were considered to cover the experimental domain. Values of the experimental responses variable ( $C$ and COD reduction) are given in Table 2 along with their predicated responses values. The predicted responses of $C$ and COD removal values were obtained from the second-order polynomial equation fitting using SAS software [Eqs. (4), (5)]. The response values $\left(f_{1}\right)$ for $\% C$ removal and $\left(f_{2}\right)$ for \%COD removal are presented by the following equations to attain the interaction between dependent and independent variables:

$f_{1}=75.53-4.29 E_{1}+1.88 E_{2}-14.92 E_{1}^{2}+2.22 E_{1} E_{2}-12.74 E_{2}^{2}$

$f_{2}=72-4.72 E_{1}+2.69 E_{2}-12.56 E_{1}^{2}-12.31 E_{2}^{2}$

where $f_{1}$ and $f_{2}$ are $\% C$ and \%COD removal of BBD from wastewater, $E_{1}$ and $E_{2}$ are the codified values of the operating parameters nanocrystals iron oxide and hydrogen peroxide concentrations, respectively. At this point, the experimental responses for $\% C$ and $\%$ COD removals are presented in Table 2. The corresponding predicted responses obtained from the models [Eqs. (4) and (5)] are very close as shown in Fig. 2, demonstrating that both values were accurate and reliable.

In order to test the suitability and the significance of the model, analysis of variance (ANOVA) was conducted using SAS software. The obtained regression equations of the polynomial models from ANOVA indicated that the correlation coefficient $\left(R^{2}\right)$ for $f_{1}$ and $f_{2}$ are 98.47 and 98.80 , respectively. This indicates a good correlation between experimental and predicted models. In fact, the quality of the model is well fitted when $R^{2}$ is suggested to be at least 0.80 (Arslan-Alaton et al. 2009; Tony and Bedri 2014).
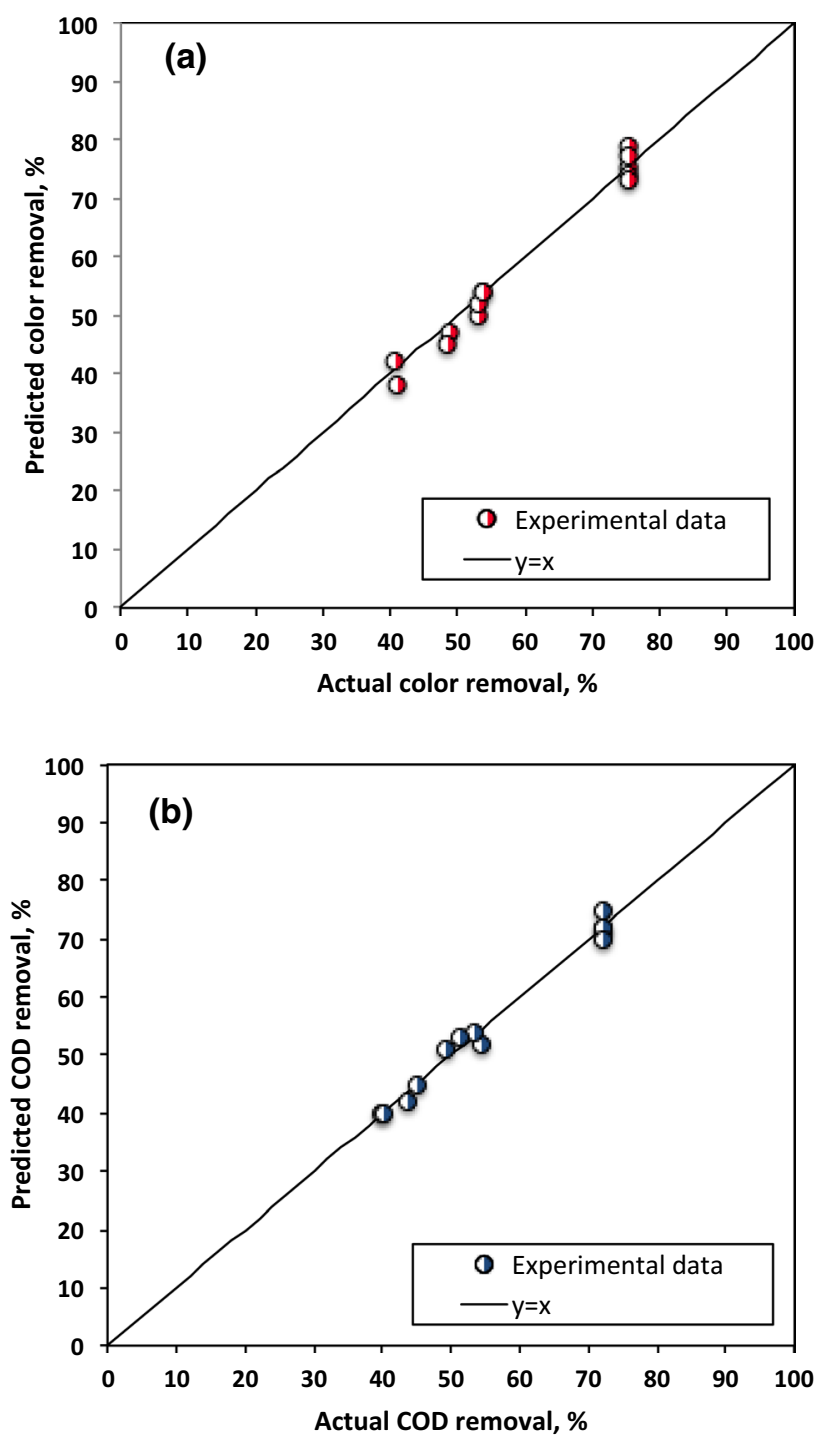

Fig. 2 Comparison between actual and predicted values of models a $f 1$ model, $\mathbf{b} f 2$ model 
In the ANOVA test of the two models presented in Table 3, the Fisher variance ratio, $F$ value is used as a measure to estimate the way that the factors explains the variation in the mean of data (Montgomery 1991). $F$ value is 89.98 for $C$ removal and 115.73 for COD removal. Simultaneously, the given very low probability ( $P$-value) $(0.0001)$ is considered significant when it is $\left(P_{\text {model }}>F\right)<0.05$ in surface response analysis (Montgomery 1991; Tony et al. 2015). Moreover, the coefficient of variation, $\mathrm{CV}$, recorded low values of $3.39 \% C$ removal model and $4.08 \%$ for COD removal model that confirms the reliability and good precision of the experimental data as recommended by Kuehl (2000). Therefore, it is concluded that the model fitted well and highly significant and the estimated factors effects are real.

\section{Effect of the investigated variables on colour and COD removal}

Subsequently, the verification of significance of the model, the suitability of the variables and interactions is identified following the Student $t$ test (Montgomery 1991).

Based on the $F$ values (Table 3), nanocrystals dose $\left(E_{1}\right)$ has significant effect $(P<0.001)$ and $(P<0.0002)$ on the responses of $C$ and COD removal $\left(f_{1}, f_{2}\right)$, respectively as it had a larger coefficient than hydrogen peroxide concentration $\left(E_{2}\right)$. The interaction effects between $E_{1}$ and $E_{2}$, were moderate. Positive coefficient of $\mathrm{H}_{2} \mathrm{O}_{2}\left(E_{2}\right)$ indicated the linear effect of increase in $f_{1}$ and $f_{2}$. However, iron nanocrystals dose $\left(E_{2}{ }^{2}\right)$ had a negative effect along with and quadratic terms $\left(E_{1}{ }^{2}\right.$ and $\left.E_{2}{ }^{2}\right)$ that decreases $f_{1}$ and $f_{2}$ responses. The positive effect of the interaction term $\left(E_{1} E_{2}\right)$ increases $f_{1}$ response. Furthermore, in order to attain a better understanding of the results, 3D surface graph and 2D contour plots were used to attain a better understanding of the results, the dependent $\left(f_{1}\right.$ and $\left.f_{2}\right)$ and independent variables $\left(E_{1}\right.$ and $E_{2}$ ) using Matlab (7.11.0.584) software. The interaction effects of $\mathrm{Fe}^{3+}$ nanocrystals and $\mathrm{H}_{2} \mathrm{O}_{2}$ concentrations on the $C$ removal efficiency presented in the 2D contour plots in Fig. $3 b$ that simulated from Eq. 4. As seen from Fig. 3a, b, the surface and contour plots showed that the $\% C$ removal was increased with increasing both the nanocrystals and $\mathrm{H}_{2} \mathrm{O}_{2}$ reagent doses. However, further increase in both reagents doses after a certain point, the reaction is retarded. This phenomenon indicates that the optimum operating conditions of $\mathrm{Fe}^{3+}$ and $\mathrm{H}_{2} \mathrm{O}_{2}$ according to colour removal are 37.21 and $412.31 \mathrm{mg} / \mathrm{L}$, respectively. Based on the maximum COD reduction, the optimum values are 36.24 and $421.88 \mathrm{mg} / \mathrm{L}$, respectively (as seen in Fig. 4a, b). Notably, this is obviously near to the optimal points with that from colour removal test.

From Figs. 3 and 4, it can be estimated that the key factor for the colour and COD removals is the nanocrystals $\mathrm{Fe}^{3+}$ concentration. However, even the hydrogen peroxide reagent effect is also important, but its effect is at a lower level. A negative effect in both responses, $C$ and COD reduction, is observed. This effect is related to the scavenging effect of radicals. However, optimal doses are needed for photoFenton reaction to occur. This could be illustrated by the increase in $\mathrm{H}_{2} \mathrm{O}_{2}$ in the presence of iron crystals resulted in the increase in. $\mathrm{OH}$ radicals generation. These radicals are the main responsible of the Fenton's reagent as those radicals are attaching the organic pollutant and mineralizing
Table 3 ANOVA for the regression model and the respective models terms

\begin{tabular}{lllllcl}
\hline Relationship & Source & $d f$ & SS & MS & $F$ & $\operatorname{Pr}>F$ \\
\hline \multirow{3}{*}{ Linear } & $f_{1}$ model & 5 & 2612.335 & 522.467 & 86.55539 & 0.0001 \\
& $E_{1}$ & 1 & 151.3691 & 151.3691 & 25.07682 & 0.001552 \\
Quadratic & $E_{2}$ & 1 & 25.51879 & 25.51879 & 4.227615 & 0.078816 \\
& $E_{1}{ }^{2}$ & 1 & 1581.19 & 1581.19 & 261.9505 & 0.0001 \\
Interaction & $E_{2}{ }^{2}$ & 1 & 1144.452 & 1144.452 & 189.5977 & 0.0001 \\
& $E_{1} E_{2}$ & 1 & 19.6249 & 19.6249 & 3.251193 & 0.114363 \\
& Error & 7 & 42.25351 & 6.036215 & & \\
\multirow{4}{*}{ Linear } & Total & 12 & 2654.588 & & & \\
& $f_{2}$ Model & 5 & 2144.824 & 428.9648 & 115.7336 & 0.0001 \\
Quadratic & $E_{1}$ & 1 & 178.5935 & 178.5935 & 48.18409 & 0.000223 \\
& $E_{2}$ & 1 & 58.08556 & 58.08556 & 15.67134 & 0.005471 \\
Interaction & $E_{1}{ }^{2}$ & 1 & 1097.852 & 1097.852 & 296.1976 & 0.0001 \\
& $E_{2}{ }^{2}$ & 1 & 1054.591 & 1054.591 & 284.5261 & 0.0001 \\
& $E_{1} E_{2}$ & 1 & 4 & 4 & 1.07919 & 0.333425 \\
& Error & 7 & 25.94539 & 3.706484 & & \\
\hline
\end{tabular}

$d f$ degrees of freedom of variance source, $S S$ sum of squares, $M S$ mean of squares (=SS/DF), $F F$ value of variance source, $P$ probability of error to be significant 

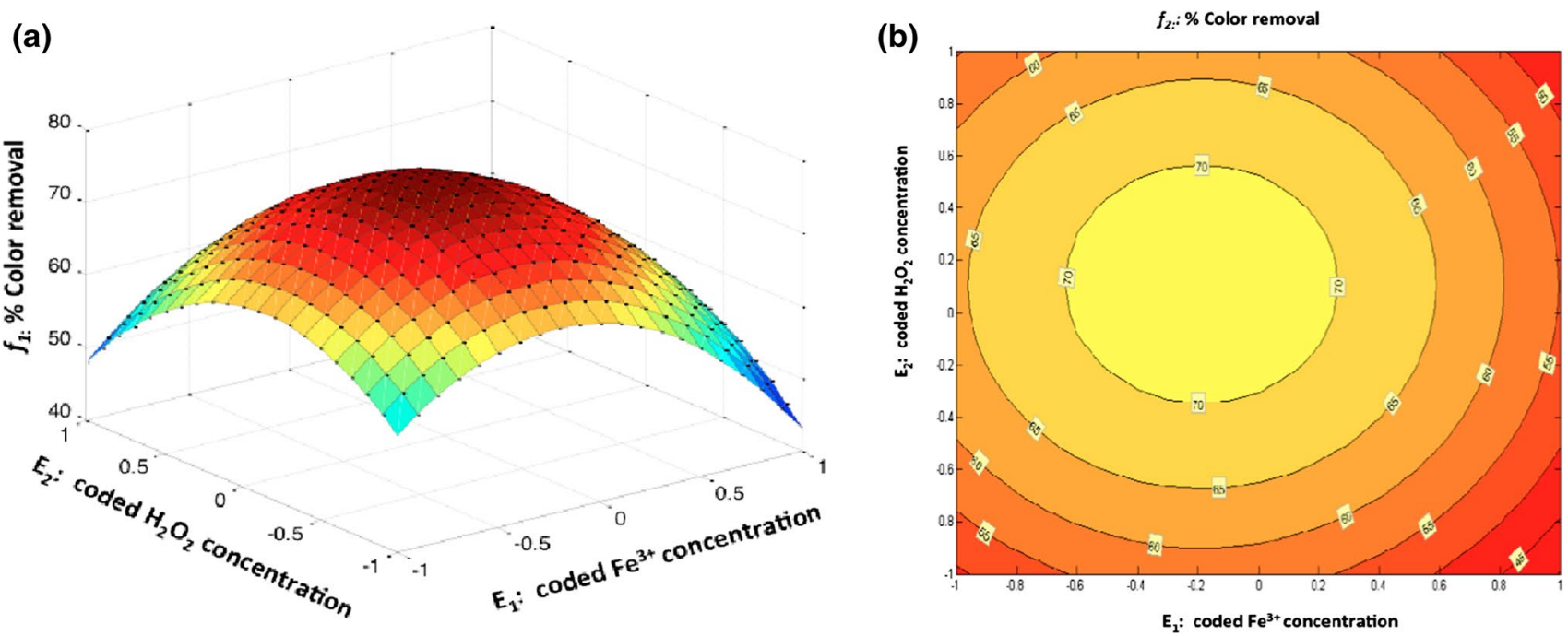

Fig. 3 Plots of colour removal response with respect to $\mathrm{Fe}^{3+}$ dose and $\mathrm{H}_{2} \mathrm{O}_{2}$ dose of photo-Fenton reaction a 3D surface plot, b 2D contour plot

(a)

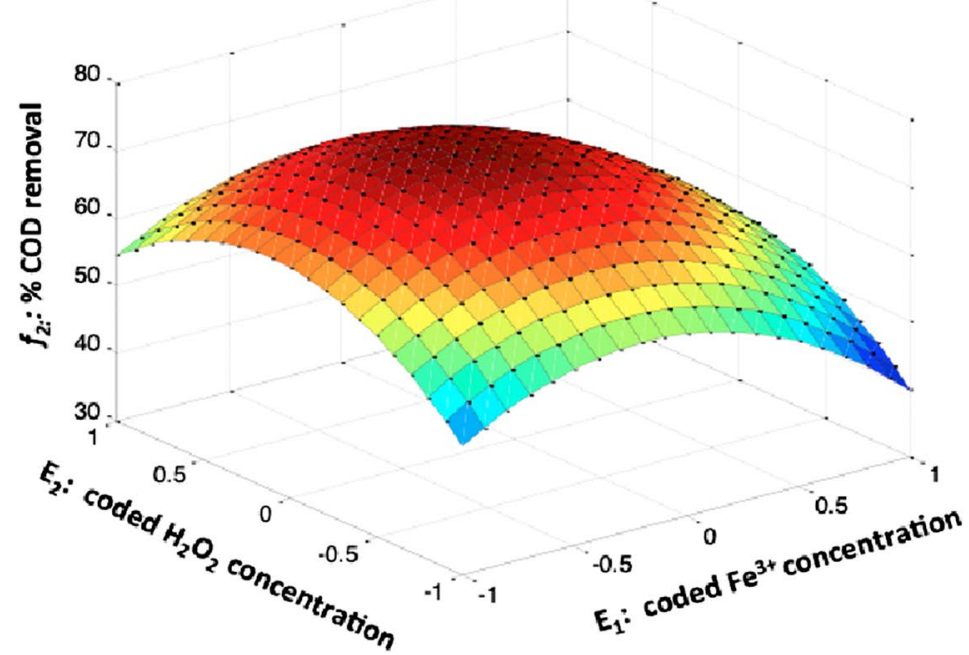

(b)

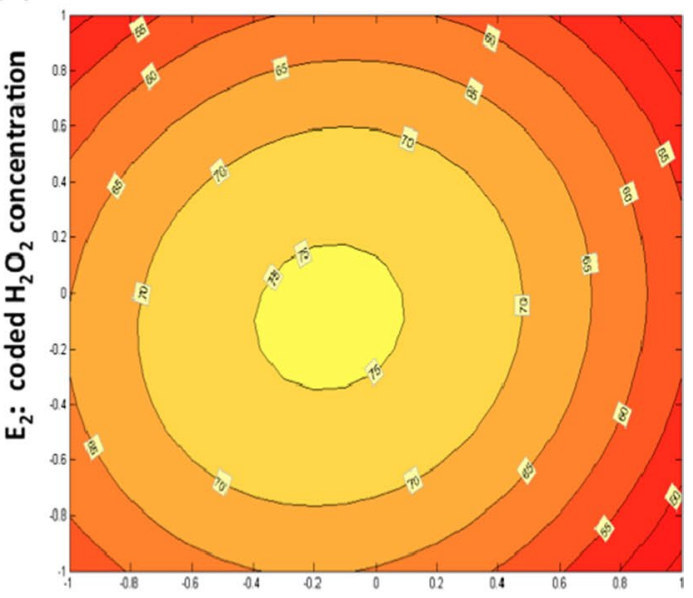

$\mathrm{E}_{1}$ : coded $\mathrm{Fe}^{3+}$ concentration

Fig. 4 Plots of COD removal response with respect to $\mathrm{Fe}^{3+}$ dose and $\mathrm{H}_{2} \mathrm{O}_{2}$ dose of photo-Fenton reaction a 3D surface plot, b 2D contour plot

them. Thus, $C$ and COD removals are enhanced. However, excessive amounts of both reagents had a determinable effect on the overall removal efficiency because of undesirable reactions that may occur between hydroperoxyl radicals and excessive amounts of $\mathrm{H}_{2} \mathrm{O}_{2}$ and $\mathrm{Fe}^{3+}$, thus, reacting with hydroxyl radicals and scavenging them according to the following equations (Tony and Bedri 2014):

$$
\mathrm{H}_{2} \mathrm{O}_{2}+\mathrm{OH} \rightarrow \mathrm{HO}_{2}+\mathrm{H}_{2} \mathrm{O}
$$

$\mathrm{Fe}^{3+}+\mathrm{HO}_{2} \rightarrow \mathrm{O}^{2}+\mathrm{Fe}^{2+}+\mathrm{H}^{+}$
$\mathrm{Fe}^{2+}+\mathrm{HO}_{2} \rightarrow \mathrm{HO}_{2}^{-}+\mathrm{Fe}^{3+}$

$\mathrm{Fe}^{2+}+\mathrm{OH} \rightarrow \mathrm{HO}^{-}+\mathrm{Fe}^{3+}$

\section{Parameters optimization within designated constraints and verification}

The optimal values for two independent variables, naoncrsyals of iron oxide and hydrogen peroxide reagents for colour and COD removals were attained using the numerical optimization future of Mathematica software (V 5.2). 
Fig. 5 Overlay contour plots for photo-Fenton optimal region of two responses

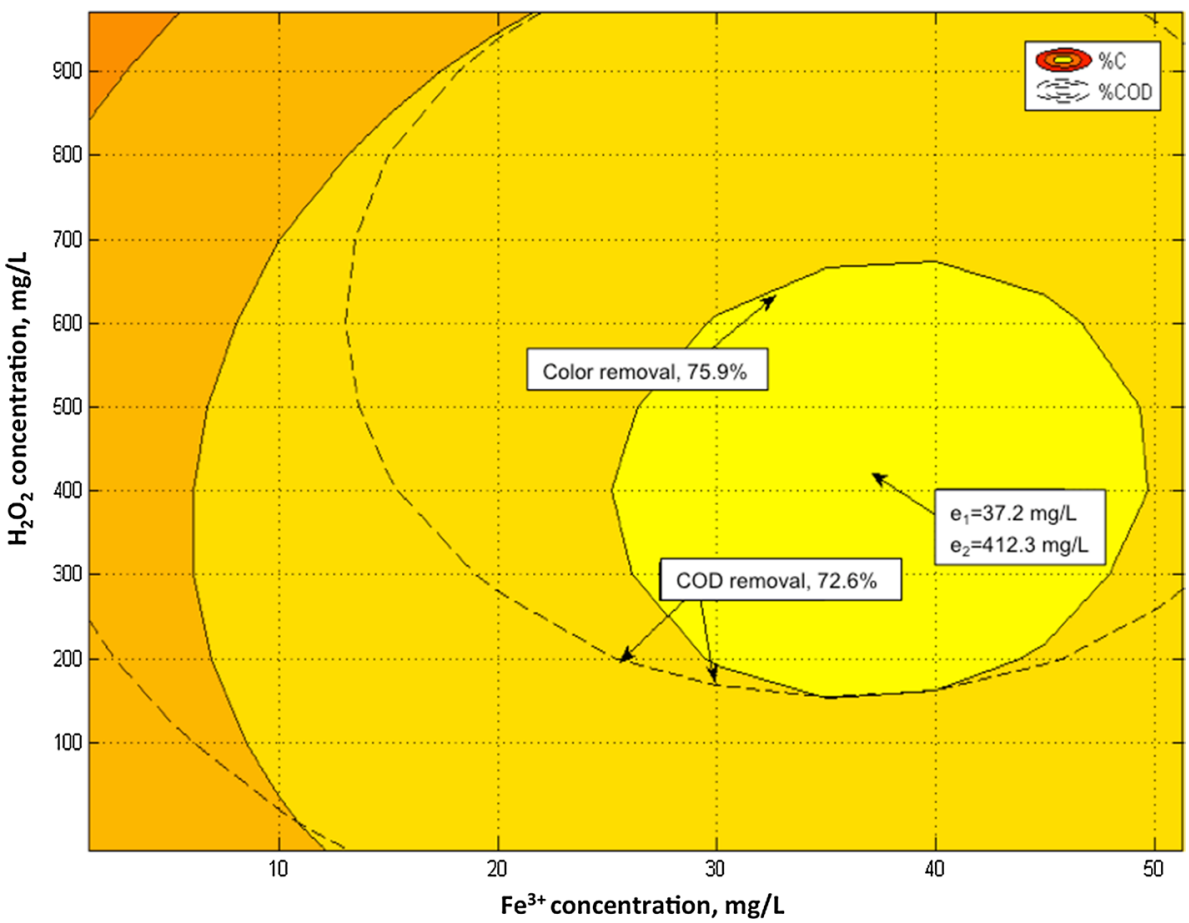

Table 4 The preset goal with the constrains for all the independent factors and responses in numerical optimization

\begin{tabular}{llll}
\hline Variables & Ultimate goal & \multicolumn{2}{c}{ Experimental region } \\
\cline { 3 - 4 } & & Lower limit & Upper limit \\
\hline Factors & & 11.72 & 68.28 \\
$\mathrm{Fe}^{3+}$ dose, $E_{1}$ & In range & 117.2 & 682.8 \\
$\mathrm{H}_{2} \mathrm{O}_{2}$ dose, $E_{2}$ & In range & & \\
Response & & 38 & 79 \\
Colour removal (\%) & Maximized & 38 & 75 \\
COD removal (\%) & Maximized & 40 & \\
\hline
\end{tabular}

Additionally, a graphical optimization presented in Fig. 5 displays the area (yellow portion zone) of feasible response values in the factors space. All the factors and responses with the particular high limit and low limit experimental region are significant and fit the standards that described the optimum values as stated in Table 4 . The optimum values for $\mathrm{Fe}^{3+}$ and $\mathrm{H}_{2} \mathrm{O}_{2}$ are 37.21 and $412.31 \mathrm{mg} / \mathrm{L}$ with maximum response of 75.9 for $C$ removal. By comparing the optimum values in Fig. 3 with Fig. 4, it can be observed that the location of optimal operating conditions from $C$ test was rational from COD test.

Ultimately, to validate the model adequacy, an additional experiment was performed using those amounts. The experimental colour and COD removals are $76.5 \%$ and $73 \%$, compared to $75.9 \%$ and $72.6 \%$, respectively, for the predicted values (Table 5). This confirms that the CCD
Table 5 Predicted and experimental values for the responses at optimum conditions

\begin{tabular}{|c|c|c|c|c|}
\hline \multirow{2}{*}{$\begin{array}{l}\mathrm{Fe}^{3+} \text { dose } \\
(\mathrm{mg} / \mathrm{L})\end{array}$} & \multirow{2}{*}{$\begin{array}{l}\mathrm{H}_{2} \mathrm{O}_{2} \text { dose } \\
(\mathrm{mg} / \mathrm{L})\end{array}$} & \multicolumn{2}{|c|}{ Colour removal (\%) } & \multirow[t]{2}{*}{ Error } \\
\hline & & Experimental & Predicted & \\
\hline \multirow[t]{3}{*}{37.21} & 412.31 & 75.9 & 76.5 & 0.6 \\
\hline & & \multicolumn{2}{|c|}{ COD removal (\%) } & \\
\hline & & Experimental & Predicted & \\
\hline 36.24 & 421.88 & 72.6 & 73 & 0.4 \\
\hline
\end{tabular}

based on RSM was a powerful tool for locating the accurate optimal values of the independent variables.

\section{Conclusion}

The performance of photo-Fenton technique for colour removal and COD reduction in BBD wastewater was investigated. Among this study, by observing the effects of interactions among the variables on colour, $C$, and COD removal efficiencies, the RSM experimental conditions were optimized. The results demonstrated significant effects of the two operating variables (iron oxide nanocrystals and hydrogen peroxide concentrations) as well as their interactive effects on the two responses. CCD was applied to locate the optimum removal rate for both responses. According to ANOVA, the proposed second-order polynomial model 
is verified and thus the model is accepted. Notably, the obtained high $R^{2}$ values for the two models are attained (98.47 and 98.80 for $C$ and COD removals, respectively) which confirms the high accuracy of the models. The predicted colour and COD removals are 75.9 and $72.6 \%$ at the optimum operating conditions at $\mathrm{pH}$ 3.0. Furthermore, the economical experimental values of the two responses maximized to $76.5 \%$ and $73 \%$ for $C$ and COD models, respectively.

Acknowledgements Scientific Research Department, Graduate Studies and Research Sector, Menoufia University, Egypt is thanked for the financial research support through a project fund.

Funding There is no funding applied through this work.

\section{Compliance with ethical standards}

Conflict of interest The author confirms there is no conflict of interest through this work.

Open Access This article is licensed under a Creative Commons Attribution 4.0 International License, which permits use, sharing, adaptation, distribution and reproduction in any medium or format, as long as you give appropriate credit to the original author(s) and the source, provide a link to the Creative Commons licence, and indicate if changes were made. The images or other third party material in this article are included in the article's Creative Commons licence, unless indicated otherwise in a credit line to the material. If material is not included in the article's Creative Commons licence and your intended use is not permitted by statutory regulation or exceeds the permitted use, you will need to obtain permission directly from the copyright holder. To view a copy of this licence, visit http://creativecommons.org/licenses/by/4.0/.

\section{References}

Abu Amr SS, Aziz HA, Bashir MJK (2014) Application of response surface methodology (RSM) for optimization of semi-aerobic landfill leachate treatment using ozone. Appl Water Sci 4:231-239

APHA-AWWA-WEF (1998) Standard methods for the examination of water and wastewater, 20th edn. American Public Health Association, Washington, DC

Arslan-Alaton I, Tureli G, Olmez-Hanci T (2009) Optimization of the photo-Fenton- like process for real synthetic azo dye production wastewater treatment using response surface methodology. Photochem Photobiol 8:628-638

Ashour EA, Tony MA (2017) Equilibrium and kinetic studies on biosorption of iron(II) and iron(III) Ions onto eggshell powder from aqueous solution. Appl Eng 1(3):65-73. https://doi. org/10.11648/j.ae.20170103.13

Ashour A, Tony MA, Purcell PJ (2014) Use of agriculture-based waste for basic dye sorption from aqueous solution: kinetics and isotherm studies. Am J Chem Eng 2(6):92-98

Babuponnusami KM (2014) A review on Fenton and improvements to the Fenton process for wastewater treatment. J Environ Chem Eng 2:557-572

Bhatia S, Othman Z, Ahmad AL (2007) Coagulation-flocculationprocess for POME treatment using Moringa oleifera seeds extract: optimization studies. Chem Eng J 133:205-212
Chen J, Qiu X, Fang Z, Yang M, Pokeung T, Gu F, Cheng W, Lan B (2012) Removal mechanism of antibiotic metronidazole from aquatic solutions by using nanoscale zero-valent iron particles. Chem Eng J 181:113-119

Hussein FH (2012) Photochemical treatments of textile industries wastewater. Asian J Chem 24:5427-5434

Kuehl RO (2000) Design of experiments: Statistical principles of research design and analysis, 2nd edn. Duxbury Press, Pacific Grove, pp 2-225

Khuri AI, Cornell JA (1996) Response surfaces: designs and analysis. Marcel Dekker, ASQA Quality Press, New York

Kumaravel GD, Anandan S, Sivasankar T (2015) Sonophotocatalytic treatment of Bismarck Brown $\mathrm{G}$ dye and real textile effluent using synthesized novel $\mathrm{Fe}(0)$-doped $\mathrm{TiO}_{2}$ catalyst. RSC $\mathrm{Adv}$ 5:10440-10451

Kotut K, Nganga VG, Kariuki FW (2011) Physico-chemical and microbial quality of greywater from Various Households in Homa Bay town. Open Environ Eng J 4:162-169

Lu MC, Chen JN, Huang HH (2002) Roleofgoethitedissolutionin the oxidation of 2-chlorophenol with hydrogen peroxide. Chemosphere 46(1):131-136

Montgomery DC (1991) Design and analysis of experiments, 3rd edn. Wiley, New York, pp 270-569

Mourabet M, El Rhilasssi A, El Boujadady H, Bennani-Ziatni M, Taitai A (2017) Use of response surface methodology for optimization of fluoride adsorption in an aqueous solution by Brushite. Arab J Chem 10:3292-3302

Nie Y, Hu C, Zhou L, Qu J, Wei Q, Wang D (2010) Degradation characteristics of humic acid over iron oxides $/ \mathrm{FeO}$ core-shell nanoparticles with UVA/ $\mathrm{H}_{2} \mathrm{O}_{2}$. J Hazard Mater 173:474-479

Parker HL, Hunt AJ, Budarin VL, Shuttleworth PS, Miller KL, Clark JH (2012) The importance of being porous: polysaccharidederived mesoporous materials for use in dye adsorption. RSC Adv 2:8992-8997

Prucek R, Hermanek M, Zboril R (2002) An effect of iron(III) oxides crystallinity on their catalytic efficiency and applicability in phenol degradation - a competition between homogeneous and heterogeneous catalysis. Appl Catal 366:325-332

Raquel O, Gonçalves CC, Botelho MC, Ramiro JE, Loureiro JM, Boaventura AR (2015) Fish canning wastewater treatment by activated sludge: application of factorial design optimization: Biological treatment by activated sludge of fish canning wastewater. Water Res Ind 10:29-38

SAS/STAT (1990) User's guide. SAS Institute Inc, Cary

Tak B, Tak B, Kim Y, Park Y, Yoon Y, Min G (2015) Optimization of color and COD removal from livestock wastewater by electrocoagulation process: application of Box-Behnken design (BBD). J Ind Eng Chem 28:307-315

Torrades F, García-Montano J (2014) Using central composite experimental design to optimize the degradation of real dye wastewater by Fenton and photo-Fenton reactions. Dyes Pigments 100:184-189

Tony MA (2019) An industrial ecology approach: green cellulose based bio-adsorbent from sugar industry residue for treating textile industry wastewater effluent. Int J Environ Anal Chem. https ://doi.org/10.1080/03067319.2019.1661397

Tony MA, Bedri Z (2014) Experimental design of photo-Fenton reactions for the treatment of car wash wastewater effluents by response surface methodological analysis. Adv Environ Chem. https://doi.org/10.1155/2014/958134

Tony MA, Zhao YQ, El-Sherbiny MF (2011) Fenton and Fentonlike AOPs for alum sludge conditioning: effectiveness comparison with different $\mathrm{Fe}^{2+}$ and $\mathrm{Fe}^{3+}$ salts. Chem Eng Commun 198(3):442-452 
Tony MA, Purcell PJ, Zhao YQ, Tayeb AM, El-Sherbiny MF (2015) Kinetic modeling of diesel oil wastewater degradation using photo-Fenton process. Environ Eng Manag J 14(1):11-16

Tony MA, Parker H, Clark JH (2016) Treatment of laundrette wastewater using Starbon and Fenton's reagent. J Environ Sci Health A 51(11):974-979

Tony MA, Parker HL, Clark JH (2018) Evaluating Algibon adsorbent and adsorption kinetics for launderette water treatment: towards sustainable water management. Water Environ J. https://doi. org/10.1111/wej.12412

Zhao YQ, Keogh C, Tony MA (2009) On the necessity of sludge conditioning with non-organic polymer: AOP approach. J Resid Sci Technol 6(3):151-155

Publisher's Note Springer Nature remains neutral with regard to jurisdictional claims in published maps and institutional affiliations. 